\title{
EAI Endorsed Transactions

\section{Learning and Long-Term Retention of a Complex Sensorimotor Task Within an Immersive Virtual Reality Environment in a Non-Injured Population}

\author{
Amanda E. Markham ${ }^{1, *}$, Kathrine A. Haluch ${ }^{1}$, Trevor B. Viboch ${ }^{1}$, John-David Collins ${ }^{1}$, Pinata H. \\ Sessoms ${ }^{1}$ \\ ${ }^{1}$ Warfighter Performance Department, Naval Health Research Center, 140 Sylvester Road, San Diego, CA 92106-3521, USA
}

\begin{abstract}
Task-specific training in immersive virtual reality environments (IVREs) can provide practice for skills that are transferred to real-world settings. The present study examined skill acquisition and retention of a non-injured population performing a complex, sensorimotor navigation task in the Computer Assisted Rehabilitation Environment (CAREN). Seventeen subjects participated twice weekly for 6 weeks, with follow-up visits at 3-month intervals for 1 year. Subjects performed a navigation task, where they drove a virtual boat through a scene using weight shifting and body movement. Subjects improved over time on all outcome measures. A significant effect was observed for visit number on total score, time to complete the task, number of buoys navigated successfully, and number of penalties incurred. Task-specific training in IVREs may be effective for operational skills training and rehabilitation of injured populations by employing tasks that lead to long-term retention.
\end{abstract}

Keywords: CAREN, Immersive Virtual Reality Environment, Task-Specific Training, Retention, Operational Tasks, Learning.

Received on 2 March 2017, accepted on 6 November 2017, published on 27 December 2017

Copyright (C 2017 Amanda E. Markham et al., licensed to EAI. This is an open access article distributed under the terms of the Creative Commons Attribution licence (http://creativecommons.org/licenses/by/3.0/), which permits unlimited use, distribution and reproduction in any medium so long as the original work is properly cited.

doi: 10.4108/eai.27-12-2017.153512

"Corresponding author. Email: amanda.e.markham2.ctr@mail.mil

\section{Introduction}

Task-specific training has been used successfully in a variety of injured and healthy populations [1-4] and can serve as a method of providing practice before applying the skills in real-world settings. Various studies have analyzed the effect of different methods of training a motor skill and demonstrated that mentally practicing a motor skill provides some improvement in performance [5], but it does not serve as a replacement for physical practice [6]. Immersive virtual reality environments (IVREs) have been used to augment practice of motor tasks by simultaneously challenging physical and mental performance, particularly in the field of rehabilitation [7, 8]. IVREs can provide feedback to the subject, such as body positioning, and can even incorporate physiological measurements, like heart rate and muscle activity. Some research has shown that augmented feedback in an IVRE has a direct effect on performance of a real task, indicating that components of the IVRE can directly relate to rehabilitation or training performance [9]. Distributing practice of a skill across multiple days is an important factor in optimal motor skill learning and retention [10]. Constant training is more effective for skill acquisition, while variable training is more effective for skill retention [11]. Previous work studying task-specific training of the wounded warrior has shown improvements in skill learning and retention in IVREs [4]. Additionally, in military and law enforcement populations, more realistic training scenarios have a greater physiological effect on subjects compared with less realistic training on the same skill. These scenarios have also produced greater motivation to succeed in subsequent trainings $[12,13]$. Meyer et al. noted that of vital importance in simulation training is the relevance of both the training task and multisensory cues that are presented within the training environment [14]. The more realistic the 
environment, the more transferrable the performance improvements may be.

The Computer Assisted Rehabilitation Environment (CAREN; Motekforce Link, Amsterdam, The Netherlands) is an IVRE that has the capability to provide relatively realistic training scenarios. The CAREN consists of a force plate-instrumented treadmill that sits atop a six degrees-offreedom motion platform. Visual displays are projected on a large screen and can be synchronized with the platform and/or subject movement. Although previous work has studied task-specific training of motor skills in a variety of environments among healthy and injured populations [15], including patients with stroke, traumatic brain injury (TBI), and lower-limb amputation, little is known about skill learning and retention using the unique CAREN platform. The purpose of this study was to understand the adaptation of healthy, non-injured adults performing a navigation task in an IVRE and to determine the long-term retention of this task-specific training over time.

\section{Methods}

\subsection{Subject population}

Seven male and 10 female subjects participated in this study. The mean \pm standard deviation age for subjects was $29.24 \pm 4.41$ years, and body mass index was $22.97 \pm 3.04$ $\mathrm{kg} / \mathrm{m}^{2}$. Subjects were healthy and had no known orthopaedic, neurocognitive, or other injury affecting their balance, learning, or vision. Volunteers gave written informed consent. This study was approved by the institutional review board at Naval Health Research Center.

\subsection{Task-specific training program}

The task on the CAREN involved a virtual boat navigation course in which subjects stood on the motion platform facing forward and navigated through a slalom course of 50 buoys. An upper body harness was worn for safety, and was adjusted so that the subject could move reely, but not fall off the platform. Subjects were instructed to use body movement to control the direction and speed of the virtual boat by shifting their body forward, backward, and side-toside. Reflective markers were placed on the subjects' shoulders and captured, using an optical motion capture system (Motion Analysis Corporation, Santa Rosa, CA), for interaction with the IVRE and navigation of the virtual boat through the course (Figure 1). Platform motion mimicked the movement of the boat through the course and over the waves. Subjects participated in the training twice a week for 6 weeks, for a total of 12 visits. The initial training session occurred at visit 1 , and the final training session occurred at visit 12 . Follow-up tests were also conducted up to 1 year later at 3, 6, 9, and 12 months following the 12th training visit, for a total of 16 testing sessions.

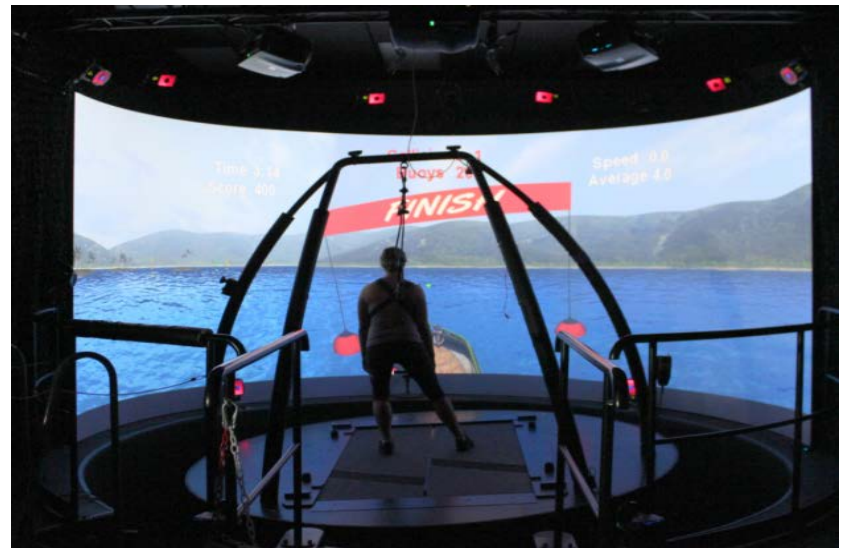

Figure 1. A subject navigates a boat through a virtual scene in the CAREN.

\subsection{Measurements}

A total score was calculated using an algorithm made of elements such as the number of buoys navigated successfully, number of objects hit (buoys [-1 point] and islands [-5 points]), time to complete the task, and specific course parameters (held constant for the sessions in this study: i.e., maximum wave height $=3 \mathrm{~m}$, and maximum boat speed $=15 \mathrm{~m} / \mathrm{s}$ ). Study outcomes included total score, number of buoys successfully navigated, penalties for objects hit, and time to complete the course.

$$
\begin{gathered}
\text { Total Score }=\left(\begin{array}{l}
\left.S_{\text {wave }}+S_{\max }\right)+\left(750-t_{\text {completion }}\right) \\
+\left[10 \times h_{\text {wave }} \times\left(b_{\text {passed }}-b_{\text {hit }}\right)\right] \\
-\left[\left(2 \times b_{\text {hit }}\right)+\left(5 \times c_{\text {hit }}\right)\right]
\end{array}\right. \\
\text { where: } \\
S_{\text {wave }}=\text { wave speed }=1.8 \\
s_{\text {max }}=\text { maximum boat speed }=15 \\
h_{\text {wave }}=\text { wave height }=3 \\
\left.t_{\text {completion }}=\text { time to complete course (in seconds }\right) \\
b_{\text {passed }}=\text { number of bouys passed } \\
b_{\text {hit }}=\text { number of bouys hit } \\
c_{\text {hit }}=\text { number of islands hit }
\end{gathered}
$$

\subsection{Statistical analyses}

A multiple regression analysis was conducted to evaluate how well each performance variable predicted the overall score. Predictors included completion time, penalties, and buoys successfully navigated, while the criterion variable was the overall task score.

A one-way repeated-measures analysis of variance was conducted to determine if there were differences in outcome measures over the 12 training visits. When Mauchly's test indicated assumption of sphericity was violated, Greenhouse-Geisser corrected tests were reported. Post hoc tests using Bonferroni correction were conducted to determine if there were significant differences between visits. Only sequential visit-to-visit scores (i.e., visit 1 
compared with visit 2, visit 2 compared with visit 3, and so on) and comparisons between visit 1 and all subsequent training visits were reported. To determine if the skills of navigating through the virtual boat task were retained, paired $t$ tests were conducted on available total scores between visit 12 and the four follow-up visits (3, 6, 9, and 12 months). Pair 1 compared results from visit 12 to the 3 month follow-up visit. Pair 2 compared results from visit 12 to the 6 month follow-up visit. Pair 3 compared results from visit 12 to the 9 month follow-up visit. Finally, Pair 4 compared results from visit 12 to the 12-month follow-up visit. These pairs were chosen to observe whether skills were retained between the last training visit (visit 12) and 3, 6,9 , and 12 months following the last training visit. Not all subjects were able to attend all four follow-up sessions, resulting in different $n$ values for each follow-up pairwise comparison. Data analyses were conducted using SPSS statistical software, version 19 (IBM, Armonk, NY). Significance was defined as $p \leq .05$.

\section{Results}

\subsection{Multiple regression analysis}

All variance inflation factors were between 1 and 2, indicating that multicollinearity was not an issue. The linear combination of performance variables was significantly related to the overall task score $(F(3,193)=923.0, p<.005$, $r^{2}=.935$, adj. $\left.r^{2}=.934\right)$, indicating the model explained more than $93 \%$ of the variance in overall score. Evaluation of each of the variables indicated all three variables (time to complete task, number of buoys successfully passed, and number of penalties) significantly contributed to prediction of the dependent variable (score) in the model. Overall score was significantly predicted by the number of penalties $(\beta=$ .30, $t(193)=-14.81, p<.005)$, task completion time $(\beta=-$ $.45, t(193)=-21.85, p<.005)$, and buoys successfully navigated $(\beta=-.49, t(193)=22.89, p<.005)$. From these results, the number of buoys successfully navigated made the strongest unique contribution to total score, followed by task completion time, and, lastly, number of penalties.

\subsection{Total score}

Total scores ranged from 1006 to 1440 points. Improvements were shown in all individuals over the 12 training visits (Table 1 and Figure 2A). Results showed a significant effect for visit number $(F(4.40,70.36)=29.975$, $p<.001)$. Post hoc comparisons indicated no significant difference in total score for any sequential visits. Average total scores over the 12 training visits significantly improved, displaying an increase of 241 points (a 21\% increase) between visit 1 and visit $12(p<.001)$. Between visits 1 and 2, mean score on the task increased by 109.71 points, the largest difference in score between consecutive visits but not significant $(p=.138)$. Other consecutive visit differences were between 0.47 and 33.18 points. All other visits (3 through 12) were significantly different from visit 1 (comparison of visits 1 and $3, p=.011$; all other visits, $p<$ $.001)$. No significant differences in scores were reported between the final training visit and any of the follow-up visits (Table 2).

Table 1. Mean (standard deviation) performance results of the boat navigation task for 12 training visits $(n=17)$.

\begin{tabular}{|c|c|c|c|c|}
\hline \multirow[b]{2}{*}{ Visit } & \multicolumn{4}{|c|}{ Variable } \\
\hline & $\begin{array}{c}\text { Total } \\
\text { Score on } \\
\text { Task } \\
\text { (points) }\end{array}$ & $\begin{array}{c}\text { Time to } \\
\text { Complete } \\
\text { Task } \\
\text { (seconds) }\end{array}$ & $\begin{array}{c}\text { Successful } \\
\text { Buoys } \\
\text { Passed } \\
\text { (number) }\end{array}$ & $\begin{array}{l}\text { Penalties } \\
\text { (number) }\end{array}$ \\
\hline 1 & $\begin{array}{c}1175.47 \\
(96.36)\end{array}$ & $\begin{array}{l}218.12 \\
(48.25)\end{array}$ & $\begin{array}{l}43.82 \\
(4.86)\end{array}$ & $\begin{array}{c}5.12 \\
(3.94)\end{array}$ \\
\hline 2 & $\begin{array}{c}1285.18 \\
(66.29)\end{array}$ & $\begin{array}{l}159.24 \\
(30.08)\end{array}$ & $\begin{array}{l}45.41 \\
(3.95)\end{array}$ & $\begin{array}{c}1.88 \\
(1.62)\end{array}$ \\
\hline 3 & $\begin{array}{c}1318.35 \\
(71.26)\end{array}$ & $\begin{array}{l}134.65 \\
(24.99) \\
\end{array}$ & $\begin{array}{l}45.88 \\
(3.22)\end{array}$ & $\begin{array}{c}1.94 \\
(2.59)\end{array}$ \\
\hline 4 & $\begin{array}{c}1334.06 \\
(65.84)\end{array}$ & $\begin{array}{l}123.59 \\
(23.73) \\
\end{array}$ & $\begin{array}{l}46.41 \\
(3.10)\end{array}$ & $\begin{array}{l}2.06 \\
(2.25)\end{array}$ \\
\hline 5 & $\begin{array}{c}1364.06 \\
(46.85)\end{array}$ & $\begin{array}{l}117.65 \\
(23.13)\end{array}$ & $\begin{array}{l}47.35 \\
(2.71)\end{array}$ & $\begin{array}{c}1.47 \\
(2.43)\end{array}$ \\
\hline 6 & $\begin{array}{c}1362.41 \\
(56.14)\end{array}$ & $\begin{array}{l}113.53 \\
(19.44)\end{array}$ & $\begin{array}{l}47.47 \\
(2.10)\end{array}$ & $\begin{array}{c}1.82 \\
(2.94)\end{array}$ \\
\hline 7 & $\begin{array}{c}1389.53 \\
(36.99)\end{array}$ & $\begin{array}{l}108.12 \\
(19.41)\end{array}$ & $\begin{array}{l}48.41 \\
(1.23)\end{array}$ & $\begin{array}{c}1.00 \\
(1.12)\end{array}$ \\
\hline 8 & $\begin{array}{c}1389.06 \\
(36.03)\end{array}$ & $\begin{array}{l}104.00 \\
(17.08)\end{array}$ & $\begin{array}{l}48.25 \\
(1.53)\end{array}$ & $\begin{array}{c}1.00 \\
(1.17)\end{array}$ \\
\hline 9 & $\begin{array}{c}1391.35 \\
(53.05)\end{array}$ & $\begin{array}{l}107.47 \\
(28.49)\end{array}$ & $\begin{array}{l}47.59 \\
(2.24) \\
\end{array}$ & $\begin{array}{c}1.94 \\
(5.24) \\
\end{array}$ \\
\hline 10 & $\begin{array}{c}1388.53 \\
(45.85)\end{array}$ & $\begin{array}{l}105.35 \\
(18.05)\end{array}$ & $\begin{array}{l}48.31 \\
(1.99)\end{array}$ & $\begin{array}{c}1.00 \\
(1.22) \\
\end{array}$ \\
\hline 11 & $\begin{array}{c}1397.94 \\
(43.28)\end{array}$ & $\begin{array}{l}100.94 \\
(16.02)\end{array}$ & $\begin{array}{l}48.35 \\
(1.17)\end{array}$ & $\begin{array}{c}.88 \\
(1.22)\end{array}$ \\
\hline 12 & $\begin{array}{c}1416.65 \\
(24.18)\end{array}$ & $\begin{array}{c}97.41 \\
(13.20)\end{array}$ & $\begin{array}{l}48.69 \\
(1.08)\end{array}$ & $\begin{array}{l}.29 \\
(.47)\end{array}$ \\
\hline
\end{tabular}

Table 2. Comparison of visit 12 and follow-up visits for total score.

\begin{tabular}{|c|c|c|c|c|c|}
\hline Pair & Variable & $\begin{array}{l}\text { Total } \\
\text { Score } \\
M(S D)\end{array}$ & $\begin{array}{c}t \\
\text { Score }\end{array}$ & $\begin{array}{c}p \\
\text { value }\end{array}$ & $95 \% \mathrm{Cl}$ \\
\hline 1 & $\begin{array}{l}\text { Visit } 12(n=9) \\
\text { 3-mo follow-up }\end{array}$ & $\begin{array}{c}1416.44 \\
(28.07) \\
1407.67 \\
(27.51) \\
\end{array}$ & .67 & .525 & $-21.66-39.22$ \\
\hline 2 & $\begin{array}{l}\text { Visit } 12(n=10) \\
\text { 6-mo follow-up }\end{array}$ & $\begin{array}{c}1414.50 \\
(27.02) \\
1422.20 \\
(19.61) \\
\end{array}$ & -.80 & .445 & $-29.53-14.13$ \\
\hline 3 & $\begin{array}{l}\text { Visit } 12(n=15) \\
\text { 9-mo follow-up }\end{array}$ & $\begin{array}{c}1416.13 \\
(24.84) \\
1415.67 \\
(27.33) \\
\end{array}$ & .05 & .958 & $-18.16-19.09$ \\
\hline 4 & $\begin{array}{l}\text { Visit } 12(n=16) \\
\text { 12-mo follow-up }\end{array}$ & $\begin{array}{c}1415.38 \\
(24.38) \\
1407.31 \\
(28.11) \\
\end{array}$ & 1.00 & .332 & $-9.08-25.21$ \\
\hline
\end{tabular}

Note: $C l$, confidence interval; $M$, mean; $S D$, standard deviation. $n$ values varied between pair numbers due to differences in the number of subjects able to attend a particular follow-up visit.

\subsection{Time to complete the task}


Time to complete the course improved over the 12 training visits (Table 1 and Figure 2B). Results showed a significant effect for visit number $(F(2.75,43.92)=74.297, p<.001)$. Post hoc comparisons revealed significant differences in number of seconds to complete the boat task between visits 1 and $2(p<.001)$, visits 2 and $3(p=.003)$, and visits 3 and $4(p=.032)$. Pairwise comparisons for additional sequential visit pairs yielded no significant results. The largest decrease in time for consecutive visits was between visits 1 and 2 (mean difference $=83.47 \mathrm{~s}$ ). In one comparison (visits 8 and 9), mean time actually increased between visits by $3.47 \mathrm{~s}$. Average completion time decreased by $120.7 \mathrm{~s}$ and was significantly different $(p<.001)$ between visits 1 and 12 . No significant differences were observed between the final training visit and any of the follow-up visits (Table 3).

Table 3. Comparison of visit 12 and follow-up visits for time to complete boat navigation task.

\begin{tabular}{|c|c|c|c|c|c|}
\hline Pair & Variable & $\begin{array}{c}\text { Time } \\
M(S D)\end{array}$ & $\begin{array}{c}t \\
\text { Score }\end{array}$ & $\begin{array}{c}p \\
\text { value }\end{array}$ & $95 \% \mathrm{Cl}$ \\
\hline 1 & $\begin{array}{c}\text { Visit } 12(n=9) \\
\& \\
\text { 3-mo follow-up }\end{array}$ & $\begin{array}{c}95.54 \\
(12.16) \\
100.33 \\
(19.41) \\
\end{array}$ & -.78 & .456 & $-19.29-9.51$ \\
\hline 2 & $\begin{array}{c}\text { Visit } 12(n=9) \\
\& \\
\text { 6-mo follow-up }\end{array}$ & $\begin{array}{c}98.44 \\
(15.80) \\
99.33 \\
(21.98) \\
\end{array}$ & -.18 & .862 & $-12.30-10.52$ \\
\hline 3 & $\begin{array}{c}\text { Visit } 12(n=16) \\
\& \\
\text { 9-mo follow-up }\end{array}$ & $\begin{array}{c}98.19 \\
(13.22) \\
98.06 \\
(15.76) \\
\end{array}$ & .04 & .969 & $-6.56-6.81$ \\
\hline 4 & $\begin{array}{c}\text { Visit } 12(n=16) \\
\& \\
\text { 12-mo follow-up }\end{array}$ & $\begin{array}{c}98.06 \\
(13.34) \\
96.75 \\
(15.99) \\
\end{array}$ & .43 & .674 & $-5.20-7.82$ \\
\hline $\begin{array}{l}\text { Note } \\
\text { Time } \\
\text { diffe }\end{array}$ & $\begin{array}{l}\text { l, confidence in } \\
\text { in seconds. } n \text { v } \\
\text { ces in the numl } \\
\text { ip visit. }\end{array}$ & $\begin{array}{l}\text { al; } M, \mathrm{~m} \\
\text { es varie } \\
\text { of subje }\end{array}$ & $\begin{array}{l}n ; S L \\
\text { etwe } \\
\text { able }\end{array}$ & $\begin{array}{l}\text { andarc } \\
\text { air nu } \\
\text { ttend }\end{array}$ & $\begin{array}{l}\text { deviation. } \\
\text { bers due to } \\
\text { particular }\end{array}$ \\
\hline
\end{tabular}

\subsection{Number of buoys navigated successfully}

The number of buoys navigated successfully increased over the 12 training visits from a mean of 43.57 to 48.57 ( $p=$ .147) (Table 1 and Figure 2C). Number of buoys successfully passed for individual subjects ranged from 35 to 53. Results showed a significant effect for visit number $(F(3.89,50.60)=4.372, p=.004)$. Post hoc results indicated no significant difference in number of buoys passed for the last training visit and follow-up visits at 3, 6, or 9 months (Table 4), but the number of buoys passed was significantly higher ( $p=.022)$ at the 12 month follow-up compared to the last training visit 12 (pair 4). Mean value differences were all within a range of .643 buoys.

\subsection{Number of penalties incurred}

The number of penalties incurred by individual subjects ranged from 0 to 20 (Table 1 and Figure 2D). Results showed a significant effect for visit number $(F(3.77,60.43)$ $=4.060, p=.006$ ), though post hoc comparisons indicated no significant difference in the number of penalties incurred for any sequential visit pairs. Average number of penalties incurred over the 12 training visits improved, decreasing by 4.82 penalties between visits 1 and $12(p=.006)$. Significant decreases occurred between visits 1 and $7(p=.025), 1$ and $8(p=.013), 1$ and $10(p=.016)$, and 1 and $11(p=.013)$. For the follow-up visits, no significant decreases were observed for the last training visit and follow-up visits at 3, 6 , or 9 months (Table 5), but the number of penalties were significantly higher $(p=.014)$ at the 12 month follow-up compared to the last training visit 12 . Mean value differences were all within a range of .81 penalties.

Table 4. Comparison of visit 12 and follow-up visits for number of buoys passed.

\begin{tabular}{|c|c|c|c|c|c|}
\hline Pair & Variable & $\begin{array}{l}\text { Buoys } \\
\text { passed } \\
M(S D)\end{array}$ & $\begin{array}{c}t \\
\text { Scor } \\
\mathrm{e}\end{array}$ & $\begin{array}{c}p \\
\text { value }\end{array}$ & $95 \% \mathrm{Cl}$ \\
\hline 1 & $\begin{array}{c}\text { Visit } 12(n=8) \\
\& \\
\text { 3-mo follow-up }\end{array}$ & $\begin{array}{l}48.75 \\
(1.16) \\
48.50 \\
(1.07) \\
\end{array}$ & .55 & .598 & $-.82-1.32$ \\
\hline 2 & $\begin{array}{c}\text { Visit } 12(n=8) \\
\& \\
\text { 6-mo follow-up }\end{array}$ & $\begin{array}{l}48.63 \\
(1.06) \\
49.25 \\
(.71) \\
\end{array}$ & $\begin{array}{c}- \\
1.49\end{array}$ & .180 & $-1.62-.37$ \\
\hline 3 & $\begin{array}{c}\text { Visit } 12(n=14) \\
\& \\
\text { 9-mo follow-up }\end{array}$ & $\begin{array}{l}48.64 \\
(1.15) \\
48.79 \\
(1.25) \\
\end{array}$ & -.33 & .745 & $-1.07-.79$ \\
\hline 4 & $\begin{array}{c}\text { Visit } 12(n=14) \\
\& \\
\text { 12-mo follow-up }\end{array}$ & $\begin{array}{c}48.79 \\
(1.05) \\
49.43 \\
(.65) \\
\end{array}$ & $\begin{array}{c}- \\
2.59\end{array}$ & .022 & $-1.18--.11$ \\
\hline
\end{tabular}

Note: $C l$, confidence interval; $M$, mean; $S D$, standard deviation. $n$ values varied between pair numbers due to differences in the number of subjects able to attend a particular follow-up visit.

Table 5. Comparison of visit 12 and follow-up visits for number of penalties incurred.

\begin{tabular}{|c|c|c|c|c|c|}
\hline Pair & Variable & $\begin{array}{c}\text { Penalties } \\
\text { incurred } \\
M(S D)\end{array}$ & $\begin{array}{c}t \\
\text { Score }\end{array}$ & $\begin{array}{c}p \\
\text { value }\end{array}$ & $95 \% \mathrm{Cl}$ \\
\hline 1 & $\begin{array}{c}\text { Visit } 12(n=9) \\
\& \\
\text { 3-mo follow-up }\end{array}$ & $\begin{array}{l}.44(.53) \\
.67(1.66)\end{array}$ & -.45 & .665 & $-1.36-.92$ \\
\hline 2 & $\begin{array}{c}\text { Visit } 12(n=10) \\
\& \\
\text { 6-mo follow-up }\end{array}$ & $\begin{array}{l}.30(.48) \\
.20(.63)\end{array}$ & .56 & .591 & $-.31-.51$ \\
\hline 3 & $\begin{array}{c}\text { Visit } 12(n=15) \\
\& \\
\text { 9-mo follow-up }\end{array}$ & $\begin{array}{l}.33(.49) \\
.27(.59)\end{array}$ & .37 & .719 & $-.32-.46$ \\
\hline 4 & $\begin{array}{c}\text { Visit } 12(n=16) \\
\& \\
\text { 12-mo follow-up }\end{array}$ & $\begin{array}{c}.31(.48) \\
1.13(1.02)\end{array}$ & -2.78 & .014 & $-1.43--.19$ \\
\hline
\end{tabular}

Note: $C l$, confidence interval; $M$, mean; $S D$, standard deviation. $n$ values varied between pair numbers due to differences in the number of subjects able to attend a particular follow-up visit. 

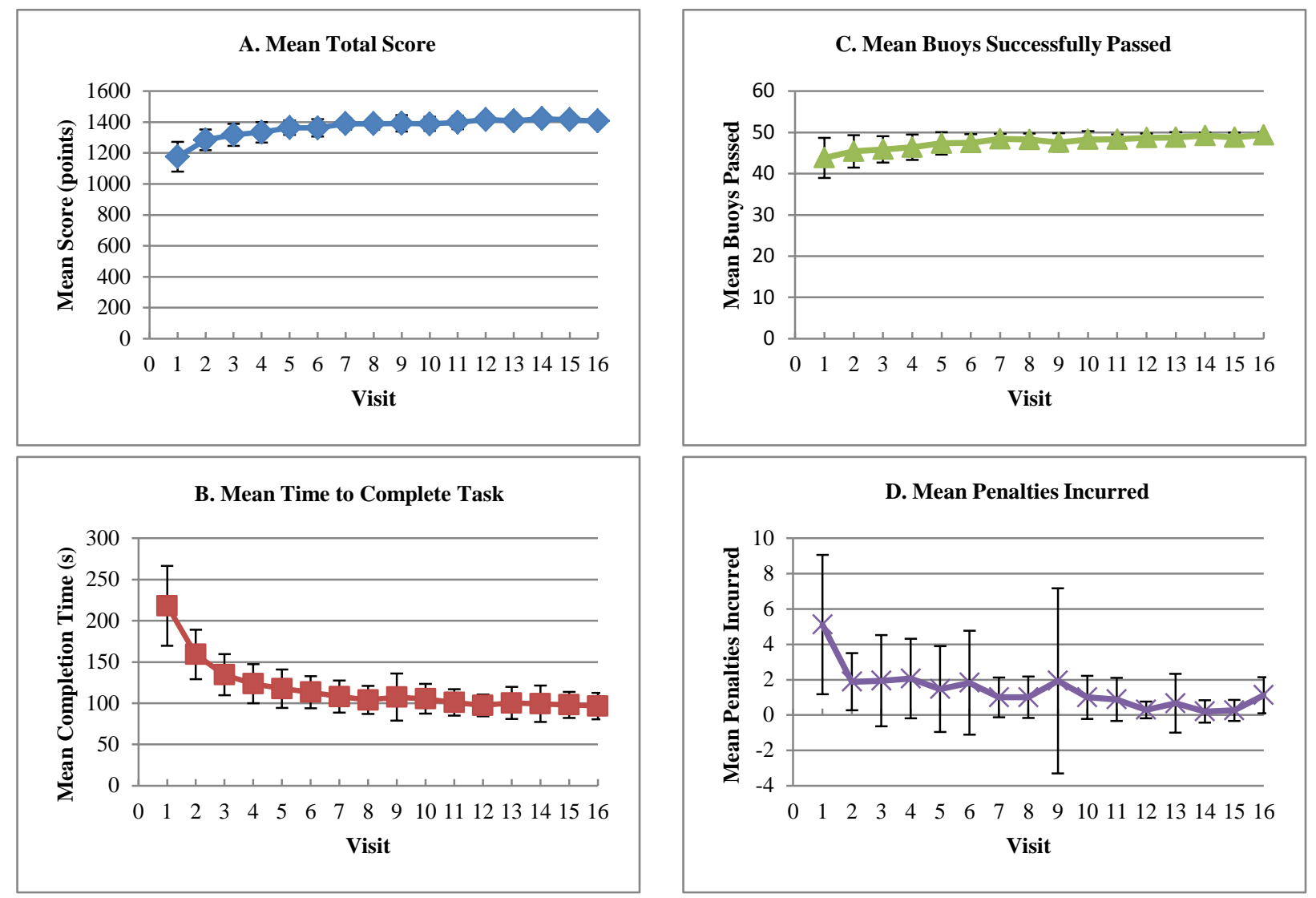

Figure 2. Mean and standard deviations of total score (A), time to complete task (B), buoys passed (C), and penalties incurred (D) across the 16 visits. Follow-up visits at 3, 6, 9, and 12 months are labeled as Visit 13, 14, 15, and 16, respectively.

\section{Discussion}

The results of this study indicate that the IVRE environment provides a platform for skill learning that is effective for both acquisition and retention. Task-specific sensorimotor skills improved with regular exposure to a navigation task in the IVRE. Additionally, these skills are retained without practice for up to 1 year following the training program. Total score and elements that comprised the total score (time to complete the boat navigation task, number of buoys navigated successfully, and number of penalties incurred) improved as a function of visit number across the 12 training visits. Although significant differences were not observed in sequential visits, there were significant improvements across the visits as a whole.

The greatest improvements in time to complete the task were observed between the first three visits, with smaller improvements thereafter. This is similar to previous work in which two groups showed progressive improvements on a timed motor sequence task between days 1 and 4 of training, reaching a plateau in performance between days 4 and 5 [10]. Other work shows improvements in military operational performance after at least three visits using IVRE training [16], including significant improvements in driving performance of military personnel who had suffered a TBI after four to six training sessions of simulated driving in an IVRE [17]. Our results match published work, showing most learning occurs within the first four sessions of training. Work in other areas related to the CAREN has shown that six training sessions is sufficient for motor training [4], but more research is needed. Though not significantly different, performance seemed to decline slightly toward some later visits (i.e., visits 8 and 10), possibly indicating subjects were becoming distracted or bored with the task, or were trying new strategies to accomplish the navigation task (risk taking). A change in strategy, also conveying higher risk taking, was observed in the final 12 month follow-up visit, as compared to the final training and any other follow-up visits, as the group seemed to perform the task faster, and with the highest accuracy (as measured by number of buoys passed), but also had more penalties due to hitting objects while navigating.

No significant differences in scores, time to complete the boat navigation task, number of buoys navigated successfully, or number of penalties incurred were observed between visit 12 compared with any of the four follow-up visits. This indicates the task-specific skill was retained long-term and provides support that the 12-visit program over the 6-week period was effective for providing the necessary training to teach and retain this specific skill for up to a year. This matches well with previous reports that 
suggest there are few declines in performance after a motor skill task is well-learned, even after a long delay with no practice [10, 18, 19]. Although IVREs are widely used in military operations training (e.g., flight simulators, infantry immersive trainers), further research demonstrating the effectiveness of training in IVREs compared with or alongside other types of instruction, such as field-based and classroom-based training, is needed.

The results from this study are useful for comparison with injured populations. Recently, researchers at Naval Health Research Center and Naval Medical Center San Diego have used the same boat navigation task in the CAREN IVRE as a method of vestibular physical therapy for wounded warriors with traumatic brain injury. Preliminary findings show patients who underwent 12 training sessions over a 6-week period started out with significantly lower scores than the non-injured control group reported in this paper, but were able to achieve similar scores by visit 12 [20]. This work provides support for the 12-visit training protocol in the CAREN IVRE as an effective program for providing task-specific training for patient populations, and it may be used to inform rehabilitation programs for other injuries, such as musculoskeletal injury or amputation.

\section{Future Directions}

The current efforts explored performance measures as a result of the training task but the underlying causal mechanisms responsible for the changes in gross motor performance are unknown. Future efforts should also explore the physiological changes in muscle activity while performing this training task. In a small, yet potentially informative sub-effort, surface electromyography data were collected in a convenience subsample of two subjects from the reported subject population. Recordings of muscle activity of the lower-limb muscles were collected at 4000 $\mathrm{Hz}$ using wireless electrodes (Trigno System, Delsys Inc., Natick, MA), during the boat task. Data were filtered using a second-order Butterworth filter with a cut-off frequency of 75-400 $\mathrm{Hz}$ and then rectified using Delsys EMGworks Software version 4.0. The root mean square envelope of the signals was calculated to examine changes in EMG amplitudes and patterns between visits. EMG signals were only used for observational findings because no recordings were taken to normalize the signal (e.g., resting or maximum voluntary contraction trials).

In these preliminary, suggestive results, an apparent trend in EMG data was observed, showing a more synchronized muscle activation pattern of the measured muscles in the later visits compared with initial visits, particularly in the thigh muscles (i.e., vastus lateralis, vastus medialis, and biceps femoris; Figures 3 and 4), which seemed to move in synchronization with the changes in direction needed to navigate through the slalom course.

These preliminary data suggest improvements in outcomes measures on the virtual environment task, such as improved total score and time to complete task, may be linked to improved muscle activation patterns across the training sessions. Previous work in motor learning tasks [21, 22] showed subjects displayed a decrease in the amount of co-contraction between agonist and antagonist muscles, and muscle recruitment became more refined as the skill or task was learned. Similar findings were observed between novice and highly trained subjects executing a motor skill [23]. The use of EMG and other physiological and biomechanical measures, combined with traditional outcomes measures on virtual tasks (i.e., game scores), may be necessary to fully understand what physical and cognitive changes are occurring to drive improvements in skill learning in a virtual task. This understanding can inform targeted training and rehabilitation programs.

Based upon these observations, it is recommended that future research explore quantitative physiological measurements. Specifically, EMG collection should incorporate amplitude analysis techniques, such as maximum voluntary contraction normalization. This will allow for observation of both muscle activity patterning, as well as magnitude, which may help determine what muscular recruitment strategies are driving improvements in task performance. Research in this area will lead to a better understanding of whether subjects learn to recruit prime movers more efficiently or incorporate other muscles into the movement. The ability to answer these questions may provide insight into how subjects are improving performance. Additionally, it is also recommended that other neurophysiological measurements, such as electroencephalography, be incorporated going forward to identify other underlying neuromotor adaptions that may be related to the learning effects observed in IVRE training and a possible method to measure engagement, and differences in strategy or decision making. Use of IVREs for training injured warfighters is not meant to replace traditional therapies, but rather provide patients with an alternative form of therapy that supports and enhances current strategies and is relevant to real-world scenarios. In addition to providing an engaging, safe and controlled learning atmosphere for training healthy and injured populations, virtual reality systems also provide a tool for objective measurement and assessment of performance. 


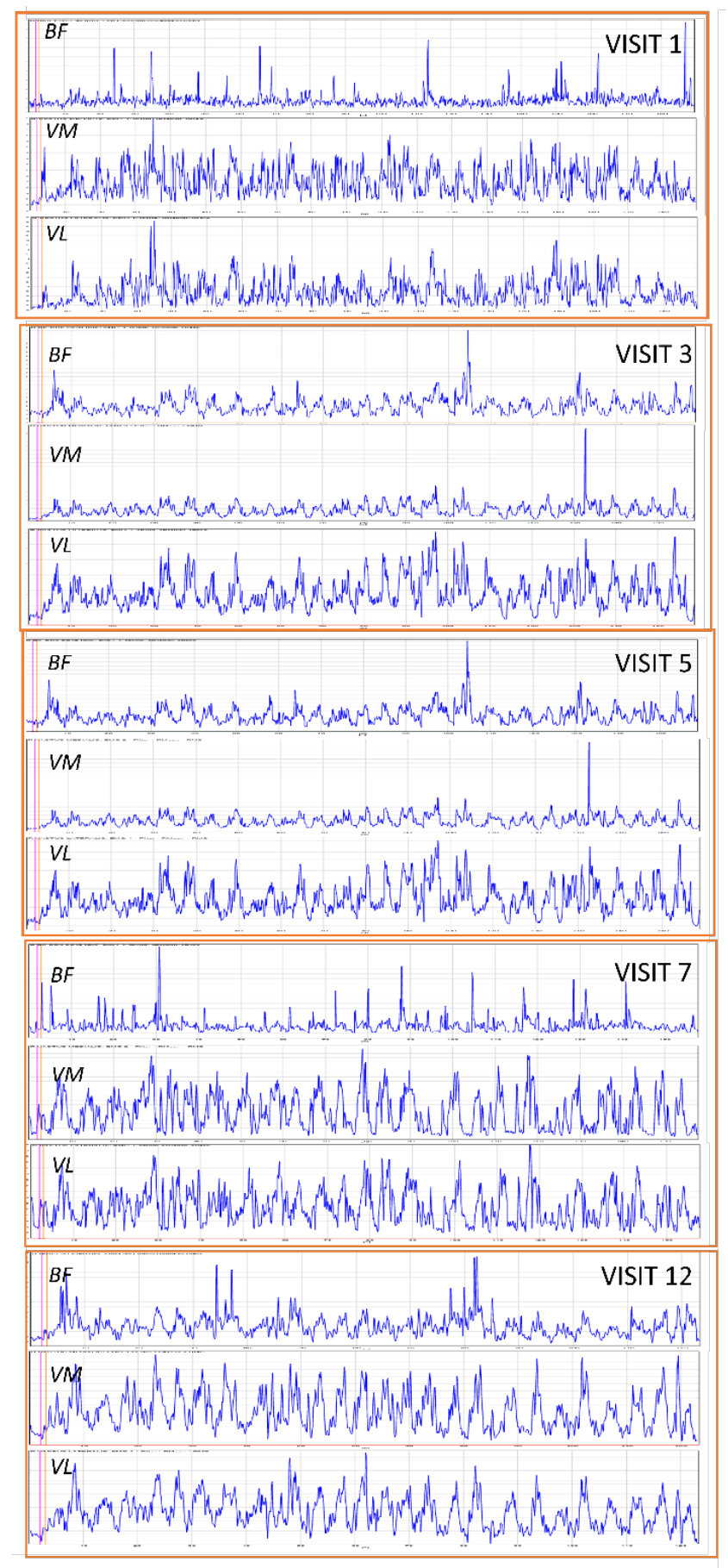

Figure 3. Example Subject A's EMG signals over the duration of the task for select lower-limb muscles (BF, biceps femoris; VM, vastus medialis; $\mathrm{VL}$, vastus lateralis) during 5 visits spanning the initial 12 training sessions. Activation patterns tended to show more refined/consistent recruitment during later visits.
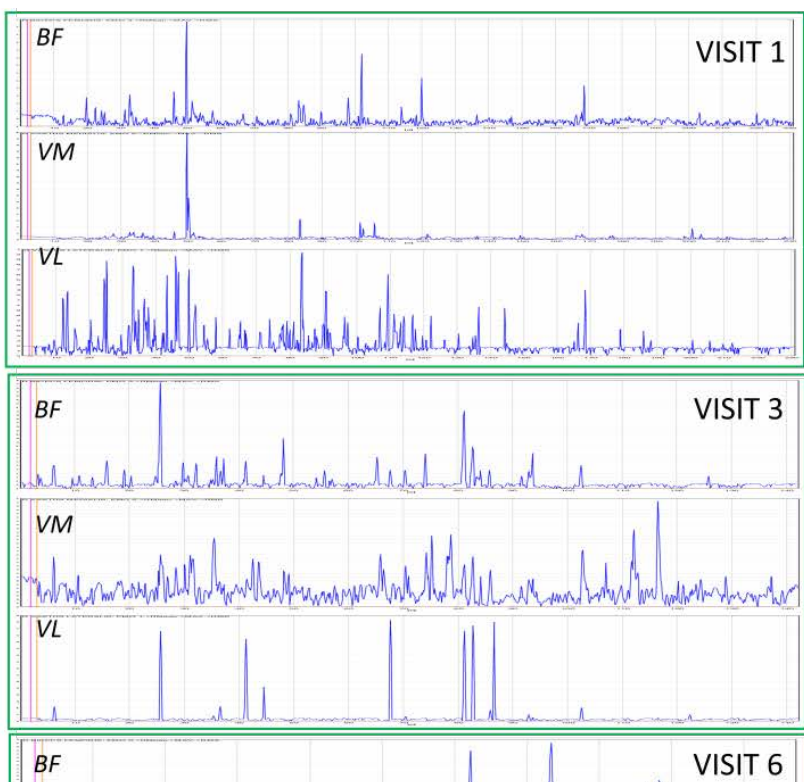

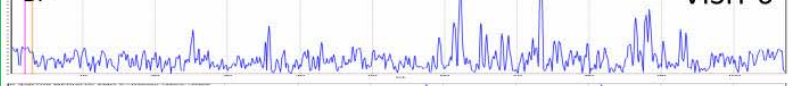

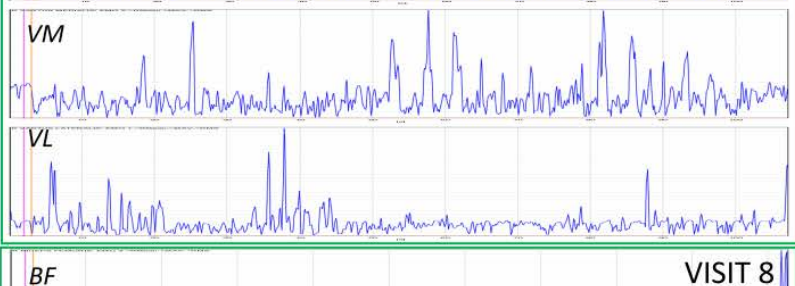
VISIT 8

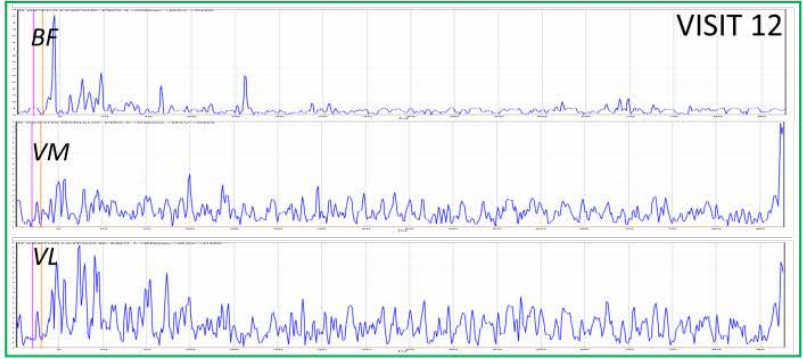

Figure 4. Example Subject B's EMG signals over the duration of the task for select lower-limb muscles (BF, biceps femoris; VM, vastus medialis; VL, vastus lateralis) during 5 visits spanning the initial 12 training sessions. Activation patterns tended to show more refined/consistent recruitment during later visits.

\section{Conclusions}

After training in an IVRE, the acquisition of a novel skill seems to be quickly acquired and retained in a healthy, noninjured population. Task-specific training in an IVRE can be useful for warfighters to acquire and practice skills before 
applying them in an operational setting. Task-specific training in the IVRE may also be useful for rehabilitating injured populations, since specific movements can be practiced while the patient is within a safe, controlled setting. Capabilities of this IVRE training have implications for returning injured warfighters to duty or civilians to highly demanding situations due to the potential for positive physical and cognitive performance gains. Details of this work can be used to plan duration of training programs in the IVRE for subjects or patients to obtain maximal performance results.

\section{Acknowledgements}

We thank LCDR Jose Dominguez, LCDR Seth Reini, Genieleah Padilla, and Jordan Sturdy for their contribution to this research, as well as Sarah Kruger from the National Intrepid Center of Excellence for her initial work on the scoring for the boat navigation task.

Disclaimer: I am an employee of the U.S. Government. This work was prepared as part of my official duties. Title 17, USC $\S 105$ provides the "Copyright protection under this title is not available for any work of the United States Government.” Title 17, USC $\S 101$ defines a U.S. Government work as work prepared by a military service member or employee of the U.S. Government as part of that person's official duties.

Report No. XX-XX supported by the Navy Bureau of Medicine and Surgery Wounded, Ill, and Injured grant R116, under work unit no. 60818. The views expressed in this article are those of the authors and do not necessarily reflect the official policy or position of the Department of the Navy, Department of the Army, Department of the Air Force, Department of Veterans Affairs, Department of Defense, or the U.S. Government. Approved for public release; distribution unlimited.

Human subjects participated in this study after giving their free and informed consent. This research has been conducted in compliance with all applicable federal regulations governing the protection of human subjects in research (Protocol NHRC.2010.0012).

\section{References}

[1] Nadeau, S.E., Wu, S.S., Dobkin, B.H., Azen, S.P., Rose, D.K., Tilson, J.K., CEN, S.Y., DunCan, P.W. and THE LEAPS INVESTIGATIVE TEAM. (2013) Effects of task-specific and impairment-based training compared with usual care on functional walking ability after inpatient stroke rehabilitation: LEAPS Trial. Neurorehabilitation and Neural Repair, 27(4): 370-380.

[2] Grabiner, M.D., Bareither, M.L., Gatts, S., Marone, J. and TroY, K.L. (2012) Task-specific training reduces triprelated fall risk in women. Medicine and Science in Sports and Exercise, 44(12): 2410-2414.

[3] Ross, J.C., Trainor, J.L., Eppich, W.J. and Adler, M.D. (2013) Impact of simulation training on time to initiation of cardiopulmonary resuscitation for first-year pediatrics residents. Journal of Graduate Medical Education, 5(4): 613619.

[4] Kaufman, K.R., Wyatt, M.P., Sessoms, P.H. and GRABINER, M.D. (2014) Task-specific fall prevention training is effective for warfighters with transtibial amputations.
Clinical Orthopaedics and Related Research, 472(10): 30763084.

[5] FeLTZ, D.L. and LANDERs, D.M. (1983) The effects of mental practice on motor skill learning and performance: a metaanalysis. Journal of Sport and Exercise Psychology, 5(1): 2557.

[6] Hird, J.S., Landers, D.M., Thomas, J.R. and Horan, J.J. (1991) Physical practice is superior to mental practice in enhancing cognitive and motor task performance. Journal of Sport and Exercise Psychology, 13(3): 281-293.

[7] Holden, M., Todorov, E., Callahan, J. and Bizzi, E. (1999) Virtual environment training improves motor performance in two patients with stroke: case report. Neurology Report, 23(2): 57-67.

[8] Holden, M.K. (2005) Virtual environments for motor rehabilitation: review. Cyberpsychology and Behavior, 8(3): 187-211.

[9] Todorov, E., Shadmehr, R. and Bizzi, E. (1997) Augmented feedback presented in a virtual environment accelerates learning of a difficult motor task. Journal of Motor Behavior, 29(2): 147-158.

[10] Savion-Lemieux, T. and Penhune, V.B. (2005) The effects of practice and delay on motor skill learning and retention. Experimental Brain Research, 161(4): 423-431.

[11] Memmert, D. (2006) Long-term effects of type practice on the learning and transfer of a complex motor skill. Perceptual and Motor Skills, 103(3): 912-916.

[12] Taverniers, J. and De Boeck, P. (2014) Force-on-force handgun practice: an intra-individual exploration of stress effects, biomarker regulation, and behavioral change. Human Factors, 56(2): 403-413.

[13] Oudejans, R.R. (2008) Reality-based practice under pressure improves handgun shooting performance of police officers. Ergonomics, 51(3): 261-273.

[14] Meyer, G.F., Wong, L.T., Timson, E., Perfect, P. and White, M.D. (2012) Objective fidelity evaluation in multisensory environments: auditory cue fidelity in flight simulation. PLos One, 7(9): e44381.

[15] Collins, J.D., Markham, A., Service, K., Reini, S., Wolf, E. and SEssoms, P. (2015) A systematic literature review of the use and effectiveness of the Computer Assisted Rehabilitation Environment for research and rehabilitation as it relates to the wounded warrior. Work, 50(1): 121-129.

[16] Pleban, R.J., Matthews, M.D., Salter, M.S and Eakin, D.E. (2002) Training and assessing complex decision-making in a virtual environment. Perceptual and Motor Skills, 94(3 Pt 1): 871-882.

[17] Cox, D.J., Davis, M., Singh, H., Barbour, B., Nidiffer, F.D., Trudel, T., Mourant, R. and Moncrief, R. (2010) Driving rehabilitation for military personnel recovering from traumatic brain injury using virtual reality driving simulation: a feasibility study. Military Medicine, 175(6): 411-416.

[18] Shadmehr, R. and Brashers-Krug, T. (1997) Functional stages in the formation of human long-term motor memory. Journal of Neuroscience, 17(1): 409-419.

[19] Fleishman, E.A. and Parker, J.F. (1962) Factors in the retention and relearning of perceptual-motor skill. Journal of Experimental Psychology, 64(3): 215-226.

[20] Sessoms, P.H., GotTshall, K.R., Collins, J.D., MARKham, A.E., SERVICE, K.A. and REINI, S.A. (2015) Improvements in gait speed and weight shift of persons with traumatic brain injury and vestibular dysfunction using a virtual reality Computer-Assisted Rehabilitation Environment. Military Medicine, 180(3 Suppl): 143-149. 
[21] Huang, H.J., Kram, R. and Ahmed, A.A. (2012) Reduction of metabolic cost during motor learning of arm reaching dynamics. Journal of Neuroscience, 32(6): 2182-2190.

[22] Moore, S.P and Marteniuk, R.G. (1986) Kinematic and electromyographic changes that occur as a function of learning a time-constrained aiming task. Journal of Motor Behavior, 18(4): 397-426.

[23] Chapman, A.R., Vicenzino, B., Blanch, P. and Hodges, P.W. (2008) Patterns of leg muscle recruitment vary between novice and highly trained cyclists. Journal of Electromyography and Kinesiology, 18(3): 359-371. 